\title{
APLIKASI PENGENALAN HURUF,GAMBAR DAN WARNA PADA PAUD MUTIARA SARI PODOREJO KECAMATAN PRINGSEWU BERBASIS ANDROID
}

\author{
Suyono'), Rina Wati ${ }^{2}$ \\ Prodi Sistem Informasi, STMIK Pringsewu Lampung \\ E-mail : yono.psw@gmail.com \\ Prodi Manajemen Informatika, STMIK Pringsewu Lampung \\ E-mail : rinastmik12@gmail.com
}

\begin{abstract}
Abstrak
Kemajuan teknologi informasi dan semakin pesatnya perkembangan perangkat lunak baik komputer maupun android yang masuk dalam era globalisasi yang tak terpisahkan dari masyarakat modern yang didalam tujuan penelitian ini yaitu membuat suatu aplikasi android pengenalan huruf, gambar, dan warna untuk murid PAUD mutiara sari podorejo kecamatan pringsewu dengan pengumpulan data menggunakan metode observasi yang tahapannya dengan melakukan pengamatan secara riil atau langsung, metode interview dengan melakukan pendekatan secara langsung dengan tahapan yang terstruktur, metode kepustakaan yaitu dengan melalui referensi jurnal-jurnal serta referensi dari buku yang sesuai. Adapun metode pengembangan sistem yang digunakan yaitu dengan metode SDLC (system development live cycle) yang di dalamnya terdapat : 1.Tahap perencanaan yaitu proses merencanakan pembuatan aplikasi android, 2.Tahap analisis yaitu mencari bahan apa saja yang akan dilakukan oleh user dan bagaimana dalam membuat aplikasi pengenalan huruf, gambar, dan warna, 3.Tahap desain yaitu membuat suatu rancangan desain aplikasi, 4.Tahap uji coba yaitu melakukan suatu uji coba pada aplikasi yang sudah dibangun, 5.Tahap implementasi yaitu menggunakan secara langsung aplikasi tersebut, 6.Tahap pengelolaan yaitu dengan merawat, memantau atau memperhatikan sistem aplikasi. Hasil dari kesimpulan penelitian aplikasi ini yaitu berjalan dari sistem operasi android dan dikhususkan atau ditunjukkan untuk anak PAUD mutiara sari podorejo kecamatan pringsewu.
\end{abstract}

Kata Kunci : Android, Huruf, Gambar, Warna, PAUD

\section{PENDAHULUAN}

Kemajuan teknologi informasi dan semakin pesatnya perkembangan perangkat lunak baik komputer maupun android yang masuk dalam era globalisasi yang tak terpisahkan dari masyarakat modern seperti saat ini yang semua kalangan usia menggunakan android, hal ini membuat pihak Paud Mutiara Sari Podorejo harus lebih maju dalam sistem pengenalan atau pembelajaran untuk muridnya. Pada faktanya pembelajaran dalam pengenalan huruf,gambar dan warna pada paud tersebut masih menggunakan sistem manual yaitu dengan gambar yang ada pada kertas yang biasa dijual dipasaran atau ditoko-toko atk,sehingga diperlukannya suatu perubahan dalam pembelajaran tersebut dengan memanfaatkan teknologi android sehingga murid-murid yang menuntut ilmu di pendidikan anak usia dini tersebut lebih bersemangat dalam belajar.

Sebagai bentuk komitmen terhadap agenda pendidikan global tahun 2030, Pemerintah Indonesia telah membuat terobosan dengan mengeluarkan kebijakan pelayanan dasar PAUD untuk anak usia 5 sampai dengan 6 tahun yang wajib dipenuhi pemerintah daerah. "Sebagaimana tertuang dalam Peraturan Pemerintah Nomor 2 Tahun 2018 tentang Standar Pelayanan Minimal," jelas Dirjen Harris. Sementara itu, Rektor Universitas YARSI, Fasli
Jalal, menyampaikan Indonesia memiliki anak usia PAUD 0-6 tahun sebanyak 26-27 juta. Saat ini, kesadaran orang tua sudah sangat baik dan lompatan akses sudah meningkat. Selain itu sumber dana juga sangat bervariasi mulai dari Dana Desa, Anggaran Pendapatan dan Belanja Daerah (APBD), Corporate Social Responsibility (CSR), dan sebagainya.[1]

Menurut irwamati*,Erfan Hasmin*,Sitti Aisa,(2017) Smartphone lebih mudah dibawa kemana - mana, bentuk fisiknya yang kecil serta kemampuan komputerisasinya yang tidak kalah cepat dengan komputer konvensional menjadi solusi dalam membangun media pembelajaran pengenalan huruf dan angka berbasis android. Dengan aplikasi ini, dapat membantu anak - anak bisa dengan mudah dan nyaman belajar mengenal huruf dan angka karena sangat mudah dibawa kemanapun. Tahap penelitian yang dilakukan dimulai dari pengumpulan bahan dan alat, analisis kebutuhan sistem, pengkodean, pengujian aplikasi dan implementasi.[2] Menurut Hero Wintolo*, Anggit Tri Widiastuti, (2015) Pengenalan warna pada anak dilakukan dengan menggunakan perangkat lunak yang diinstal pada smartphone yang menggunakan metode image to speech. Metode ini diharapkan akan lebih mudah dilakukan dan hasilnya diharapkan akan maksimal karena smartphone peralatan saat ini harga sangat terjangkau dan sering 
digunakan oleh anak-anak usia dua sampai dengan tiga tahun untuk bermain game.[3] Menurut Amrulloh*,Ari Mulyoto,(2016) Adanya aplikasi animasi pembelajaran interaktif pada PAUD, para murid tidak merasa bosan lagi dalam belajar dan lebih cepat menghafal. Para guru pun lebih fokus dalam mengajar dan waktu belajar mengajar menjadi lebih efisien.[4] Menurut Nurul Fitriyani*, Dewi Tresnawati*, Nahdi Hadiyanto, (2014) "Metode penelitian dalam pengembangan aplikasi pengenalan huruf, angka dan warna ini menggunakan metode Pengembangan Multimedia versi Luther-Sutopo dan untuk pengujian aplikasi menggunakan metode pengujian Black Box dan pengujian beta terhadap kepuasan pengguna. Hasil dari penelitian ini berupa aplikasi pengenalan huruf, angka dan warna untuk anak usia dini berbasis android yang memiliki fitur dua bahasa yaitu bahasa indonesia dan bahasa inggris"'[5]

Dari empat penelitian diatas akan dikembangkan yang dalam penelitian ini akan mempunyai suatu perbedaan supaya dapat lebih meningkatkan minat belajar anak-anak. Dan Aplikasi dalam penelitian ini menggabungkan dari tiga elemen penelitian yang sudah disebutkan diatas seperti huruf,gambar dan warna.

Masalah yang ditemukan saat melakukan penelitian yaitu menyusun logika saat pembuatan software menuntut peneliti untuk memahami logika khususnya logika pada mit app inventor, sedangkan logika yang digunakan dalam mit app inventor mendekati dengan logika yang digunakan saat membangun aplikasi menggunakan bahasa pemrograman bahasa java. Selebihnya tidak ada kendala yang berlebih dalam menciptakan aplikasi ini.

Dalam penelitian kali ini gambaran aplikasi yang dibuat yakni menggunakan mit app inventor dan memiliki ouput berupa kumpulan huruf-huruf seperti huruf alfabet dan huruf hijaiyah, gambargambar dasar seperti gambar buah, gambar hewan, gambar alat transportasi untuk anak paud dan warnawarna pengenalan dasar seperti merah, kuning, hijau dan biru beserta warna lainnya untuk anak paud.

\section{METODE PENELITIAN}

\subsection{Metode Pengumpulan Data}

Dalam melakukan penelitian ini untuk mendapatkan data dan informasi, maka metode yang digunakan dalam proses pengumpulan data yaitu sebagai berikut :

\section{Metode Observasi}

Pada tahapan ini dengan menggunakan metode observasi peneliti akan melakukan suatu pengamatan secara riil atau langsung untuk melihat bagaimana proses belajar yang sedang berlangsung pada Paud Mutiara Sari di desa Podorejo. Dari hasil observasi peneliti dapat mengetahui bagaimana proses belajar tersebut untuk mengambil suatu kesimpulan.

2. Metode Interview

Pada tahapan ini dengan menggunakan metode interview yang terstruktur peneliti akan melakukan pendekatan secara langsung dengan guru-guru dan juga orang tua wali murid dari Paud mutiara sari podorejo kecamatan pringsewu untuk memperoleh suatu informasi atau data guna untuk mempermudah para murid dalam mendapatkan pembelajaran dalam pengenalan hufur, gambar dan warna dengan mudah.

\section{Metode Kepustakaan}

Dalam tahap ini peneliti juga menggunakan metode kepustakaan (study pustaka) yang berupa dari referensi jurnal-jurnal (peneliti terdahulu) serta dari referensi buku yang sesuai.Dalam hal ini peneliti mencari, mengumpulkan, mempelajari dan merangkum informasi yang relevan dan akurat dari jurnal-jurnal maupun dari buku yang berkaitan dengan pengenalan huruf, gambar dan warna pada murid paud mutiara sari podorejo.

\subsection{Metode Pengembangan Sistem}

Dalam buku Muhamad Muslihudin, Oktafianto (2016), Metode penelitian ini menggunakan SDLC (system development live cycle) merupakan pola yang diambil untuk mengembangkan suatu sistem perangkat lunak, yang terdiri dari beberapa tahap seperti : perencanaan , analisis, implementasi, desain, uji coba serta pengelolaan.[10]

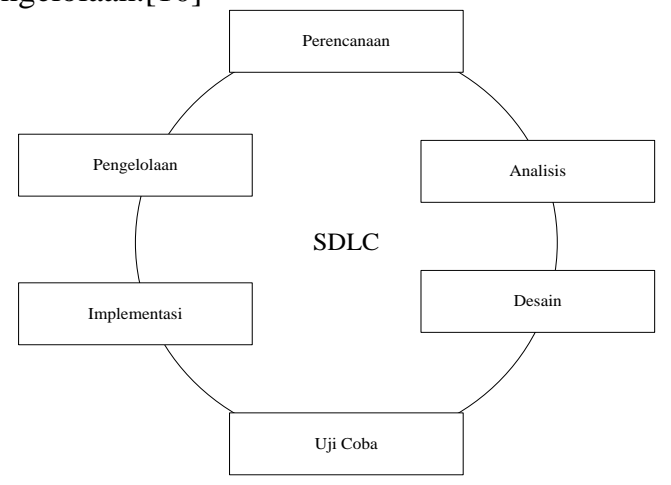

Gambar 1. Bagan Metode SDLC

1.Tahap Perencanaan

Pada tahapan ini dilakukannya suatu perencanaan proses pembuatan aplikasi android dengan mempelajari suatu browser mit app inventor atau bahasa pemograman yang lainnya yang berkaitan dengan android.

2.Tahap Analisis

Pada tahapan ini yaitu mencari bahan apa saja yang dilakukan oleh user dan bagaimana membuat aplikasi android pengenalan huruf, gambar dan warna ini menjadi sesuatu yang memudahkan bagi para murid dalam belajar dan para orang tua mudah mengajarai anak-anaknya dirumah.

3.Tahap Desain 
Pada tahapan ini yang dilakukan yaitu membuat suatu rancang bangun untuk membantu dalam menyusun pembuatan suatu aplikasi android yang dimana tahapan-tahapan ini meliputi desain interface, fungsi aplikasi dan kemudahan dalam penggunaan.

4.Tahap Uji Coba

Pada tahapan ini yaitu melakukan suatu uji coba pada aplikasi pengenalan huruf, gambar dan warna yang dibuat serta dikoreksi supaya tidak adanya terjadi suatu permasalahan atau error pada saat sistem dijalankan dan supaya sesuai dengan hasil yang diharapkan.

5.Implementasi

Pada tahapan ini yaitu menggunakan secara langsung aplikasi pengelan huruf, gambar dan warna dengan objek yang sesungguhnya. Dimana objek tersebut adalah murid paud mutiara sari podorejo kecamatan pringsewu.

6.Tahap Pengelolaan

Pada tahapan ini yaitu untuk merawat, memantau atau memperhatikan sistem aplikasi yang dirancang atau dibuat agar tidak menimbulkan masalah ataupun terjadinya suatu kendala dalam sistem tersebut.

\subsection{Kerangka Pikir Penelitian}

Didalam penelitian ini menjelaskan mengenai tahapan atau prosedur-prosedur mengenai pengenalan huruf, gambar dan warna dengan basis aplikasi android yang bertujuan untuk mempermudah bagi para murid dan juga guru dalam proses pembelajaran mengenai pengelan huruf, gambar, dan juga warna tersebut.

Berikut adalah alur pada penelitian yang dimulai dari awal persiapan dalam menentukan suatu tujuan dalam penelitian hingga akhir penelitian.

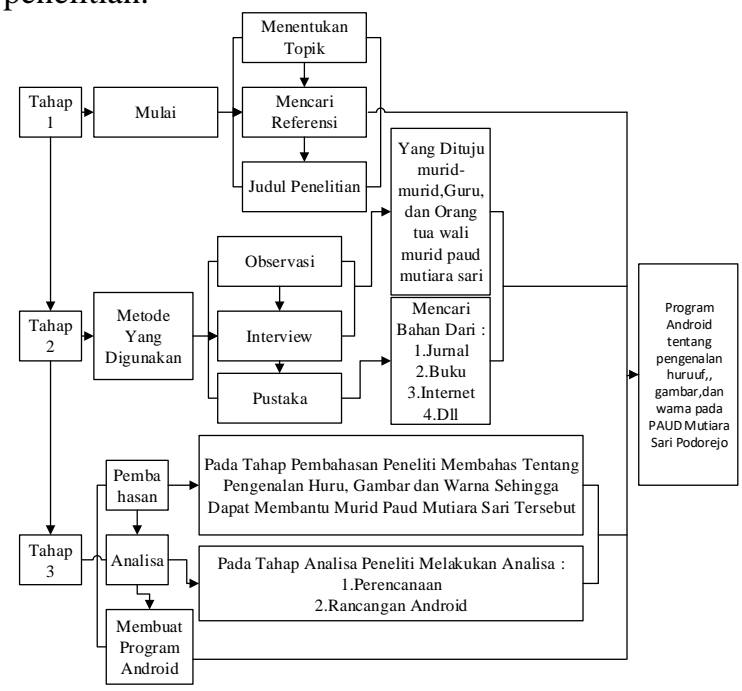

Gambar 2. Alur Penelitian

Keterangan :

\section{Tahap Penelitian Awal}

Jurnal Ilmiah “Technologia"
Tahap ini merupakan tahap awal dalam pembuatan jurnal. Penelitian ini yang terdiri dari menentukan topik penelitian, dan mencari referensi, dan menentukan judul penelitian.

2. Tahap Pengumpulan Data

Tahap ini menggunakan metode observasi, interview, dan studi pustaka.

3. Tahap Analisis Data

Setelah pengumpulan data diatas selesai selanjutnya dilakukan analisis terhadap data. Hal ini bertujuan untuk melakukan pengelompokan terhadap data tersebut sehingga dapat memudahkan penulis di dalam melakukan analisis berikutnya.

4. Tahap Pembuatan Sistem

Tahap ini membahas tentang rangcangan dan pembuatan sistem android pengenalan huruf, gambar, dan warna.

5. Tahap Implementasi Sistem

Tahapan berikutnya yang aka dilakukan dalam penelitian yaitu menggunakan secara langsung aplikasi android yang telah dibuat tentang pengenalan huruf, gambar, dan warna untuk murid-murid pada paud mutiara sari di desa podorejo.

\section{HASIL DAN PEMBAHASAN \\ Perancangan Sistem}

Pada gambar dibawah ini memperlihatkan flowchart perancangan pembuatan sistem android pengenalan huruf, gambar, dan warna pada paud mutiara sari desa podorejo, yaitu dari menganalisa suatu sistem yang dibutuhkan dan suatu adanya data fakta yang ada, setelahnya membuat suatu desain sistem lalu dilanjutkan dengan evaluasi sistem tersebut cocok atau tidaknya dengan yang diinginkan, jika benar maka dilanjutkan dengan implementasi system dan selesai.

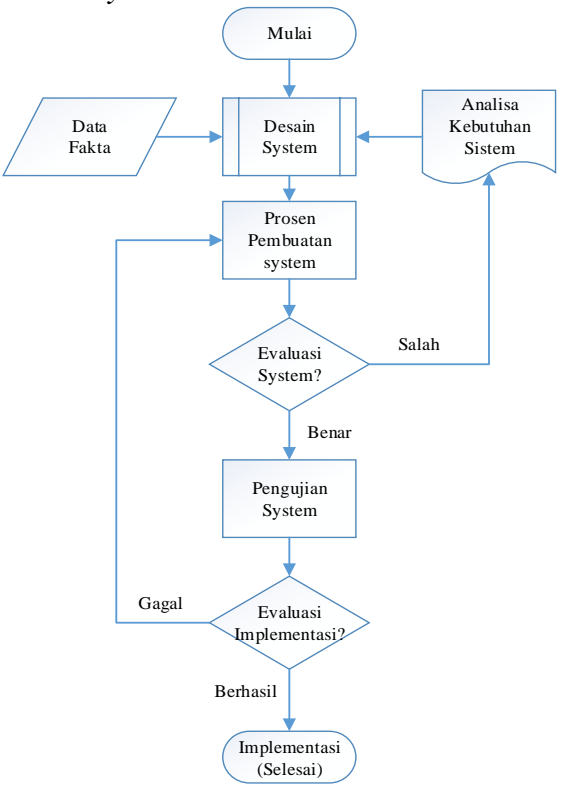

Gambar 3. Alur Perancangan Sistem 


\section{Implementasi}

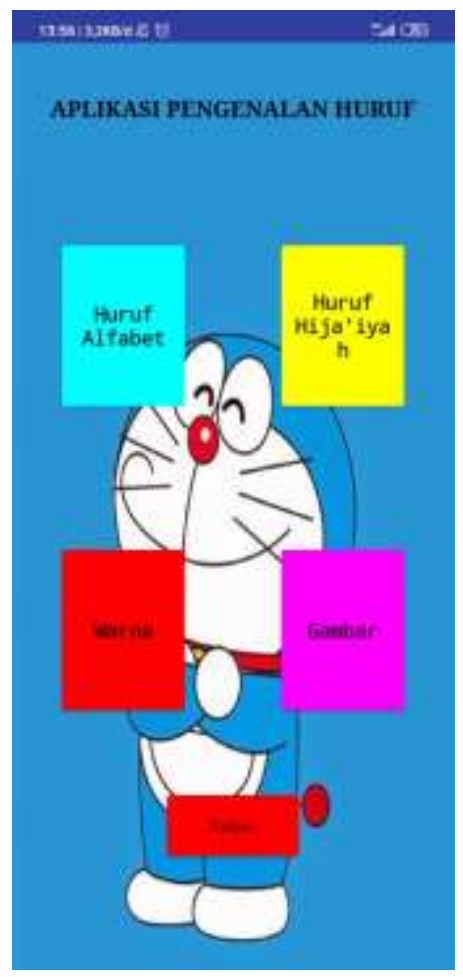

Gambar 4. Halaman Awal

Tampilan layar awal untuk memulai aplikasi peengenalan huruf, gambar, dan warna. Pada halaman awal ini berisi fitur-fitur dengan pilihan huruf alfabet, huruf hija'iyah, warna, dan gambar.

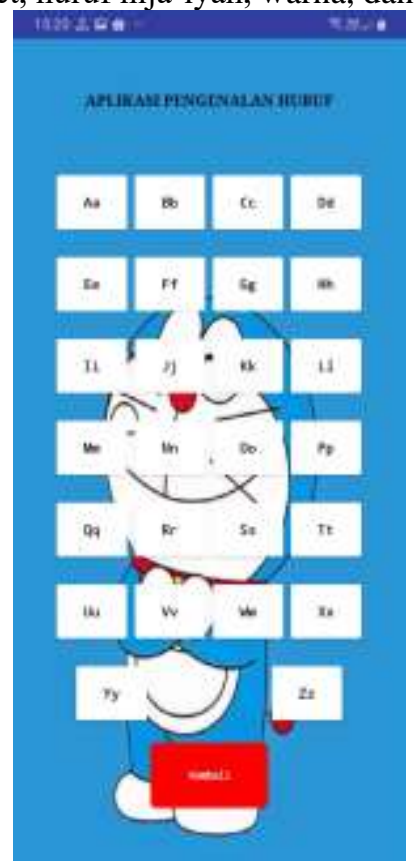

Gambar 5. Tampilan Huruf Alfabet

Tampilan huruf alfabet dimana nantinnya para murid paud mutiara sari pada desa podorejo tersebut dapat belajar dengan meng-klik fitur huruf dan juga terdapat suara ejaan yang ada pada masing-masing huruf.

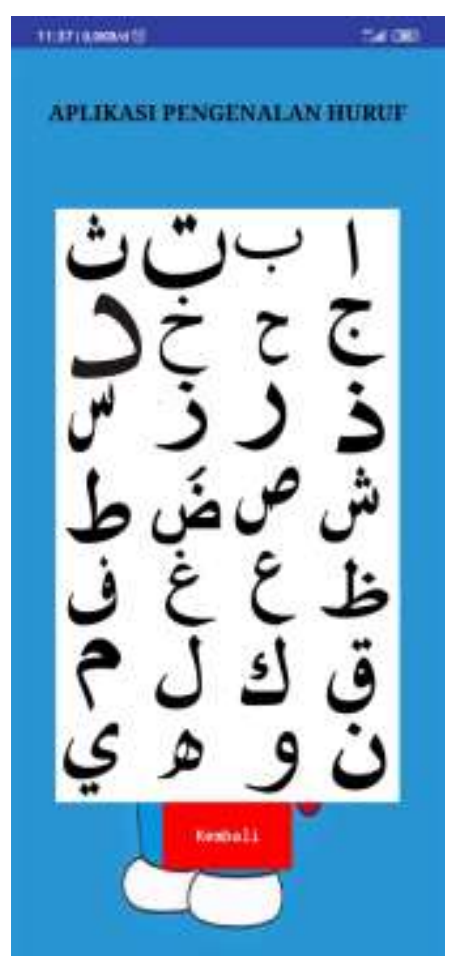

Gambar 6. Tampilan Huruf Hija’iyah

Tampilan huruf hija'iyah dimana nantinnya para murid paud mutiara sari pada desa podorejo tersebut dapat belajar dengan meng-klik fitur huruf hija'iyah dan juga terdapat suara lafadz yang ada pada masing-masing huruf hija'iyah. 


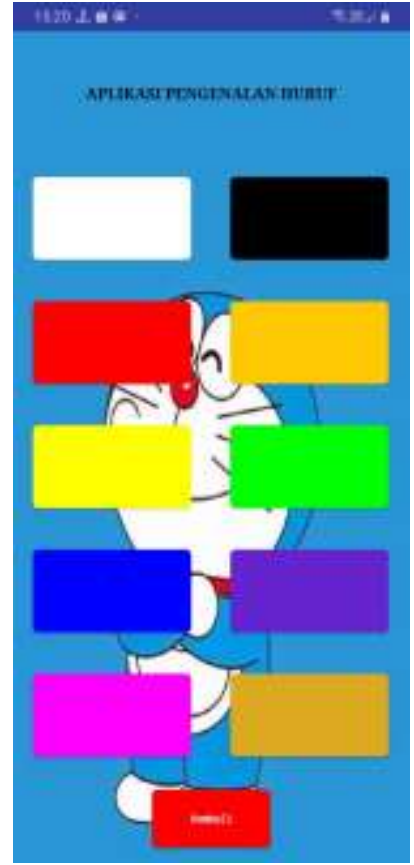

Gambar 7. Tampilan Fitur Warna

Tampilan fitur warna dasar yang nantinya di klik fitur warna dan juga terdapat suara keterangan tiap warna tersebut.

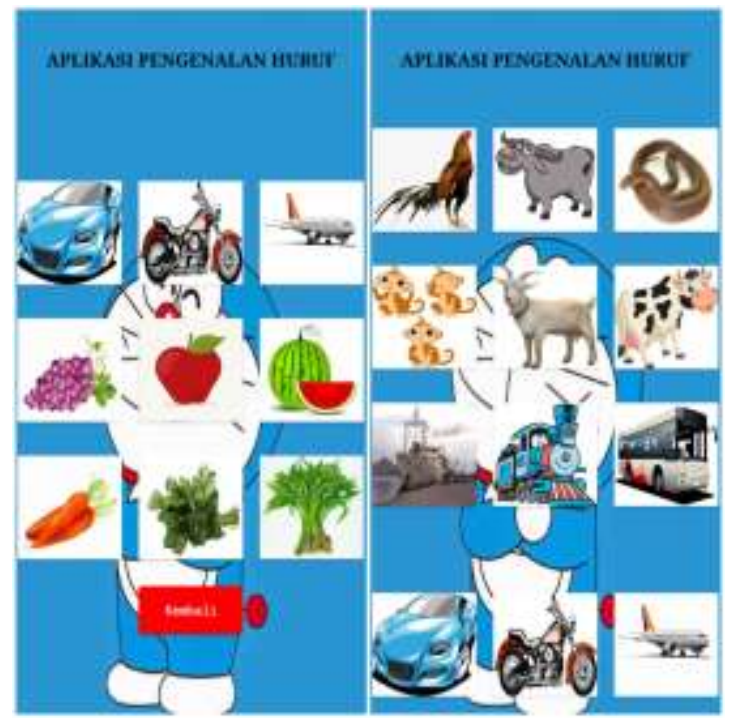

Gambar 8. Tampilan Pengenalan Gambar

Tampilan pengenalan gambar dimana dalam fitur tersebut terdapat suatu gambar transportasi darat, laut, dan udara. Lalu ada pula hewan, buah, dan sayuran dengan meng-klik fitur gambar tersebut terdapat suara keterangan pada tiap gambar.

\section{KESIMPULAN}

Dari hasil pembahasan mengenai aplikasi pengenalan huruf, gambar, dan warna diatas diantaranya untuk mempermudah sistem Jurnal Ilmiah "Technologia" pembelajaran untuk para murid agar semakin lancar dalam membaca baik dalam abjad alfabet maupun hija'iyah dan lebih semangat dalam belajar.

\section{REFERENSI}

[1] Kemendikbud, "PAUD dan Pendidikan Keluarga Penting Dalam Mendukung Perkembangan Anak," 2019. [Online]. Available:

https://www.kemdikbud.go.id/main/blog/20 19/11/paud-dan-pendidikan-keluargapenting-dalam-mendukung-perkembangananak. [Accessed: 10-Jan-2020].

[2] S. A. Irmawati, Erfan Hasmin, "PERANCANGAN APLIKASI PENGENALAN HURUF DAN ANGKA BERBASIS ANDROID STUDI KASUS : TK ROS ANGGRIANY," no. November, pp. 1-6, 2017.

[3] H. Wintolo and A. T. Widiastuti, "PEMANFAATAN IMAGE TO SPEECH BERBASIS ANDROID UNTUK PENGENALAN WARNA BAGI ANAK BAWAH TIGA TAHUN," pp. 1-12.

[4] A. Mulyoto, "ANIMASI PEMBELAJARAN INTERAKTIF UNTUK ANAK 4-5 TAHUN BERBASIS ANDROID," vol. 1, no. 2, pp. 38-42, 2016.

[5] N. Fitriyani et al., "Pengembangan aplikasi pengenalan huruf, angka dan warna untuk anak usia dini berbasis android," pp. 273281.

[6] M. A. M. Sri Mulyani, Leny Suzan, Yusar Dagara, Erlynda Yuniarti K, Christine Dwi karya S, Zahra Nur Azizah K, SISTEM INFORMASI AKUNTANSI: APLIKASI DISEKTOR PUBLIK. Unpad Press, 2019, 2019.

[7] G. W. Fachrul K, CEPAT MENGUASAI PEMOGRAMAN ANDROID. Universitas Brawijaya Press, 2015, 2015.

[8] MA.Muazar Habibi, ANALISIS KEBUTUHAN ANAK USIA DINI (Buku Ajar S1 PAUD). Deepublish, 2018, 2018.

[9] M. K. Ikhsan Parinduri,S.Si.,M.Si, Helmi Fauzi Siregar,ST.,M.Kom, Iskandar, Pengontrolan Suhu Kelembapan Kumbung Jamur Tiram Putih. Green Press, 2017, 2017.

[10] O. Muhamad muslihudin, ANALISIS dan Perancangan Sistem Informasi Menggunakan Model Terstruktur dan UML. Penerbit Andi, 2016. 